\title{
Molecular hydrogen encapsulation in spherophanes
}

\author{
Amar Saal $^{\mathrm{a}, \mathrm{b}, *}$, Thibaut Jarrosson ${ }^{\mathrm{c}}$, Ourida Ouamerali ${ }^{\mathrm{b}}$, Claude A. Daul ${ }^{\mathrm{a}}$ \\ ${ }^{a}$ Department of Chemistry, University of Fribourg Chemin du muse 9, 1700 Fribourg, Switzerland \\ ${ }^{\mathrm{b}}$ LPCTCI Laboratory, Faculty of Chemistry, USTHB University El Alia, 16111 Algiers, Algeria \\ ${ }^{\mathrm{C}}$ Institut Charles Gerhardt de Montpellier, Equipe AM2N 34296, France
}

\begin{abstract}
Molecular hydrogen insertion in and release from four molecular containers, spherophanes, have been studied with different computational methods. It has been found that dispersion interactions are very important in these systems; they govern their stability and the potential energy barriers. The calculated energy barriers are very high so that $\mathrm{H}_{2}$ could not enter to/release from the cavity of the spherophanes through the benzene rings. The hydrogen molecule would rather prefer to follow the $4 \mathrm{H}$-approach. The M05-2X/6-31G(d) results show that the encapsulation of $\mathrm{H}_{2}$ inside these spherophanes is stabilizing. The energy barriers for $\mathrm{H}_{2}$ to enter to (to release from) the spherophanes' cages are compared with those of open fullerenes.
\end{abstract}

\section{Introduction}

The design and synthesis of new efficient hydrogen storage materials is a very active field. Many experimentalists and theorists are implicated. From the past two decades, the researchers in this domain are interested in the nanostructure compounds: nanotubes, zeolites, fullerenes, supramolecular cages, clathrates, graphite, graphite intercalated fullerenes, polymeric matrixes... have been largely investigated [1-12].

The works of Cram [13] have opened a new domain of organic chemistry: the chemistry of host-guest systems [14]. The guest molecule is imprisoned inside the host's cavity either reversibly, in hemicarcerand complexes, or permanently, in the case of carceplexes. Many investigations have been devoted to the study, the design, and the synthesis of new molecular containers. Thus, different guest molecules have been trapped in a large variety, in size and shape, of host cages [15-19]. Molecular container compounds have been used for different purposes such as: to inhibit very reactive species, to isolate molecules from their surrounding, as a chamber for micro-reactions, to store atoms, ions, or small molecules such as $\mathrm{H}_{2}$ and $\mathrm{CH}_{4}$.

The spherophanes 1-4, Scheme 1 , are being synthesized by one of us. Their electronic and geometrical structures, their thermochemistry as well as some of their spectroscopic data have been investigated at different model of computational chemistry [20]. In this work, we studied a molecular hydrogen encapsula-

\footnotetext{
* Corresponding author. Address: Department of Chemistry, University of Fribourg Chemin du muse 9, 1700 Fribourg, Switzerland.

E-mail addresses: amar.saal@unifr.ch (A. Saal), thibaut.jarrosson@enscm.fr (T. Jarrosson), oouamerali@hotmail.com (O. Ouamerali), claude.daul@unifr.ch (C.A. Daul).
}

tion in these molecular cages. These spherophanes possess cavities with different sizes where $\mathrm{H}_{2}$ is supposed to be inserted in. The intermolecular interaction potential between the system's two molecules, $\mathrm{H}_{2}$ and spherophane, has been evaluated at the semi-empirical levels AM1 [21] and PM3 [22], at Hartree-Fock [23-25], and using the hybrid density functionals B3LYP [26,27] and M05-2X [28].

The two interacting molecules in the considered systems $\left(\mathrm{H}_{2}\right.$, Spher) are neither polar nor charged thus at long distances the only interaction energy responsible of the attraction is the dispersion correlation energy. The usual computational methods such as B3LYP, HF which have been successfully used for the prediction of molecular geometrical structures and thermochemistry are no longer valid for the description of van der Waals weakly bonded systems, neither do the semi-empirical ones AM1 and PM3. PostHartree-Fock methods, $\operatorname{CSSD}(\mathrm{T})$ and MP2, take into account the correlation interactions and illustrate correctly vdW interactions however their use is time consuming. Particularly, the $\operatorname{CCSD}(\mathrm{T})$ method is only used for very simple small systems.

Very recently, the development of new methods to describe the dispersion energy has become a very active field. More precisely, we site the works of Grimme [29-31] and of Truhlar et al. [28,32-35]. In this present study, we have adopted two approaches to evaluate the dispersion correction: the empirical approach of Grimme $[29,30]$ and the hybrid functional M05-2X developed by the Truhlar's group [28]. We have done rigid scan of the displacement of $\mathrm{H}_{2}$ relatively to the spherophane molecule. The intermolecular distance $\mathrm{d}$ between the mass centers of these two molecules has been varied from $0, \mathrm{H}_{2}$ is inside the spherophane, to $10 \AA$ where the two molecules are far enough one of the other so that the van der Waals interaction energy would be equal to zero. 


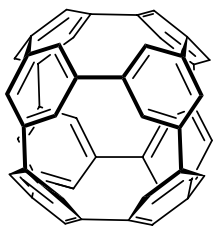

Spher1

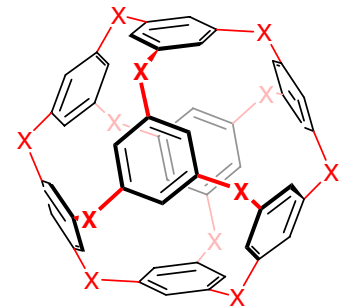

Meth2 : $\mathrm{X}=\mathrm{CH}_{2}$ Oxa3 : $\mathrm{X}=\mathrm{O}$, Thia4 : $X=S$

Scheme 1. Structures of the considered spherophanes.

In the next section we give the methodological and computational aspects. The results and their discussion are given in the third section and the fourth section is for remarks, conclusions and outlooks.

\section{Methodology and computational aspects}

All the computational works have been made using the G03 package [36]. The geometrical structures of the spherophanes have been optimized at B3LYP/6-31G(d) level followed by frequency calculations in an earlier paper [20]. In this study, we investigated the variation of the intermolecular interaction energy when a hydrogen molecule is inserted into or released from a spherophane host. We have made two sorts of calculations: (1) rigid scans for intermolecular distances varying from 0 to $10 \AA$ at different levels: semi-empirical PM3 and AM1, $a b$ initio HF, and at the hybrid density functionals B3LYP and M05-2X using the 3-21G basis set and (2) complete optimizations of the systems $\left(\mathrm{H}_{2}\right.$, Spher) at M05$2 \mathrm{X} / 6-31 \mathrm{G}(\mathrm{d})$ at five different intermolecular distances. In all what follows the abbreviation Spher refers to Spher1, Meth2, Oxa3, or Thia4.

The two involved molecules are neither charged nor polar, thus the interaction energy is essentially governed by the dispersion forces. For the M05-2X method, the weak van der Waals interactions are taken into account in the method itself [28]. However, for the other used methods, i.e. PM3, AM1, HF, and B3LYP, the dispersion correction energy has been evaluated using the empirical formula developed by Grimme [29,30]. In this approach the total energy is expressed as

$E_{\mathrm{Tot}}=E_{\mathrm{SCF}}+E_{\text {Disp }}$

where $E_{\mathrm{SCF}}$ is the usual SCF energy computed in our case at HF, B3LYP or with the semi-empirical methods AM1 and PM3, and $E_{\text {Disp }}$ is the empirical dispersion term given by

$E_{\text {Disp }}=-S_{6} \sum_{i, j} \frac{C_{6}^{i j}}{R_{i j}^{6}} f_{\mathrm{dmp}}\left(R_{i j}\right)$

where the summation is made over all the atom pairs of the system, $s_{6}$ is a global scaling factor that depends only on the used method, $R_{i j}$ is the interatomic distance between the atoms $i$ and $j, \mathrm{C}_{6}^{i j}$ is the interatomic dispersion coefficients $f_{\mathrm{dmp}}$ is a damping function which is used in order to avoid near-singularities for small distances $R_{i j}$. In this present study we have followed the parameterization used by Morgado et al. in Ref. [31].

\section{Results and discussion}

In our previous paper [20], we have studied, at B3LYP/6-31G and $6-31 G(d)$, the geometrical and electronic structures of the spherophanes as well as their thermochemistry. These molecules have been found to adopt the octahedral symmetry. In this present paper, we propose to investigate the capability of these containerlike molecules to encapsulate molecular hydrogen inside their cavities. We will try to respond to the questions: Are the dispersion interactions of importance in these systems? Is the imprisonment of $\mathrm{H}_{2}$ in these spherophanes stabilizing or destabilizing? Does the encapsulated hydrogen molecule rest at the center of the cage or not? How high are the energy barriers of $\mathrm{H}_{2}$ releasing or insertion? Which spherophane is best convenient for the encapsulation?

\subsection{Dispersion correction contribution}

Before studying and comparing the results of the insertion and release of a hydrogen molecule inside the considered spherophanes and the different ways that $\mathrm{H}_{2}$ can follow to enter into (or to exit from) the cages, we believe that it is important to analyze the dispersion effects and its contribution to the interaction energy between the two molecules of the system $\left(\mathrm{H}_{2}\right.$, Spher), where Spher is Spher1, Meth2, Oxa3, or Thia4.

Since Spher1 has a relatively small inner cavity [20], we have proposed to study the case of the system $\left(\mathrm{H}_{2}\right.$, Meth2) in $4 \mathrm{H}$-approach, Scheme 2 . The variation of the total interaction energy, $E_{\mathrm{Tot}}$ (Eq. (1)), between the hydrogen molecule and methanospherophane2 in function of the intermolecular distance $d$ is given in Fig. 1 , where $d$ has been varied between $0, \mathrm{H}_{2}$ is at the center of Meth2, and $10 \AA$. At $d=10 \AA$, the dispersion interaction between the two molecules is zero. In this Figure, the SCF energy, $E_{\mathrm{SCF}}$ (Eq. (1)), is also plotted. From the plots in Fig. 1, one can evaluate the dispersion energy contribution to the total interaction energy. At the distance $d=0$, all the energies $E_{\mathrm{SCF}}$ are almost close to zero however $E_{\mathrm{Tot}}(d=0)$ is equal to $-1.56(\mathrm{PM} 3),-1.34(\mathrm{AM} 1)$, $-2.03(\mathrm{HF}),-1.88$ (B3LYP), and $-0.95 \mathrm{kcal} / \mathrm{mol}$ (M05-2X). Thus, the system stabilization at $d=0$ is due to the dispersion interaction. Another important point is that, in the contrary of the plots of $E_{\mathrm{SCF}}=f(d)$, the $E_{\mathrm{Tot}}=f(d)$ curves show a minimal on both sides of the energy barrier. A fact which is intuitive since the two molecules $\mathrm{H}_{2}$ and Meth2 are neither charged nor polar so when they approach each other the dispersion correction prevails for certain distances before being dominated by the repulsive interaction at short distances. The energy barriers' highs are also affected by the London interaction.

\section{2. $\mathrm{H}_{2}$ insertion and release}

In the above subsection, we have highlighted the importance of the dispersion correction to the interaction energy in the considered systems. Therefore, in all the results given bellow we have taken into account the dispersion energy. We have considered two types of approaches: the $4 \mathrm{H}$-approach where the hydrogen mole-
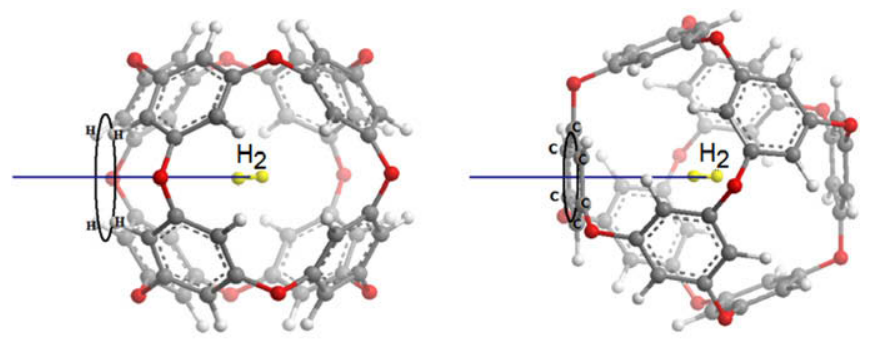

4H-Approach

6C-Approach

Scheme 2. The two approaches. 


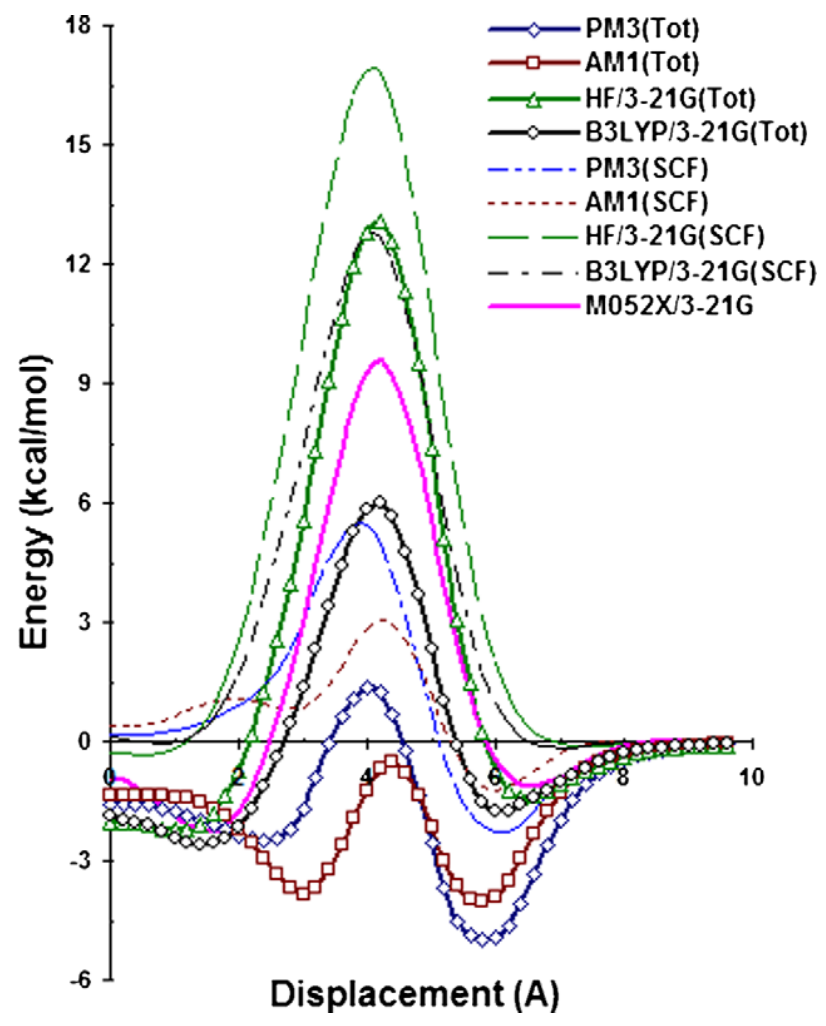

Fig. 1. SCF and total interaction energy variation in function of the intermolecular distance $\mathrm{d}$ in the system $\left(\mathrm{H}_{2}\right.$, Meth2) in the $4 \mathrm{H}$-approach, Scheme 2.

cule passes between four $\mathrm{H}$ atoms of the spherophane and the $6 \mathrm{C}$ approach where the hydrogen molecule goes through a benzene ring perpendicularly to its plan, Scheme 2 . The calculations, rigid scans, have been made at the levels AM1, PM3, HF, B3LYP and
M05-2X, with 3-21G as a basis set, for both approaches and for all the systems $\left(\mathrm{H}_{2}\right.$, Spher $)$.

\subsubsection{H-approach}

In Fig. 2, the variation of the total interaction energy is plotted in function of the intermolecular distance $d$ in the $4 \mathrm{H}$-approach. All the methods show that when the hydrogen molecule is close to the center of the spherophane, the interaction energy of the system $\left(\mathrm{H}_{2}\right.$, Spher $)$ is negative. This means that, with all the methods and for all the systems under consideration, the encapsulation of $\mathrm{H}_{2}$ inside the spherophane stabilizes the system $\left(\mathrm{H}_{2}\right.$, Spher $)$. However, it has been found that the insertion of $\mathrm{H}_{2}$ into, for example open $\mathrm{C}_{70}$ causes destabilization of $+4.0 \mathrm{kcal} / \mathrm{mol}$ [5].

For all the systems and with all the methods an energy barrier exists at the entrance of the spherophane and from both sides of this barrier a minimum in the curve has been depicted which are essentially due to the dispersion interaction. The obtained results show that the minimum inside the cavity decreases as well as the dispersion interaction increases. In the case of the smallest spherophane, Spher1, the interactions between $\mathrm{H}_{2}$ and the inner phase of its cavity are more cooperative than they are in the case of Thia4.

Globally, all the used computational models lead to the same profile of the interaction energy variation in function of $d$, Scheme 3. The graphs in Fig. 2 illustrate that the semi-empirical methods are not exactly in phase with the other used methods. At HF, B3LYP, and M05-2X, the minima inside the spherophanes are lower than those outside, $E_{2}<E_{4}$. Therefore, the energy barrier $E_{23}=E_{3}-E_{2}$, corresponding to the molecular hydrogen release from the spherophane, is greater than $E_{43}=E_{3}-E_{4}$, which corresponds to the insertion of $\mathrm{H}_{2}$, as shown in Fig. 3a. In Fig. 3a, one can remark that both $\mathrm{E}_{23}$ and $\mathrm{E}_{43}$ decrease in the order Spher1 > Oxa3 $>$ Meth2 $>$ Thia4. A result which was rather predictable since the diameter at the entrance of these spherophanes increases in the opposite order. This diameter is $2.596 \AA$ (Spher 1 ), $3.659 \AA$
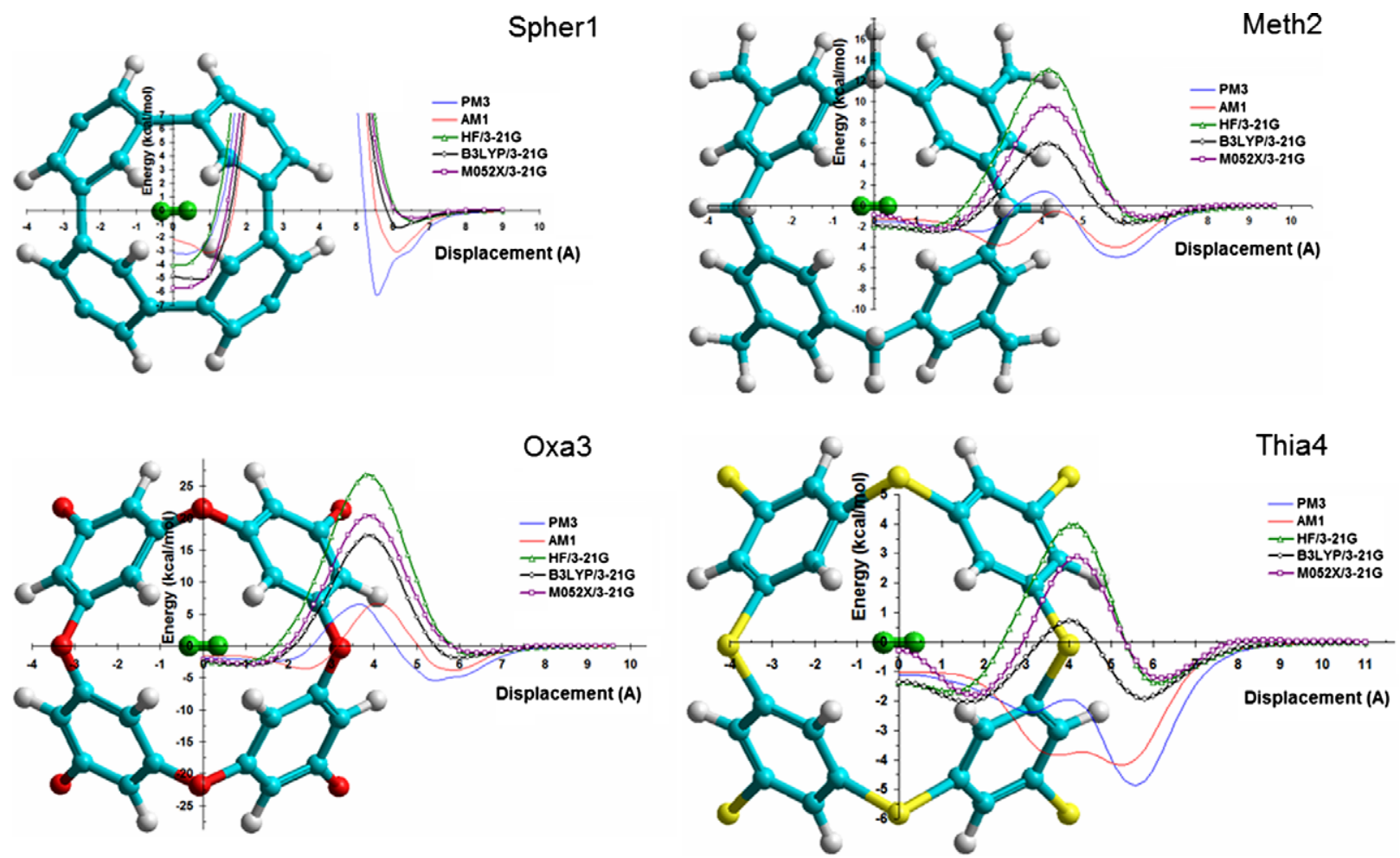

Fig. 2. Total interaction energy, $E_{\mathrm{Tot}}=E_{\mathrm{SCF}}+E_{\mathrm{Disp}}$, variation in function of the intermolecular distance $d$ in the systems ( $\mathrm{H}_{2}$, Spher) in the $4 \mathrm{H}-\mathrm{approach}$, Scheme 2 . 


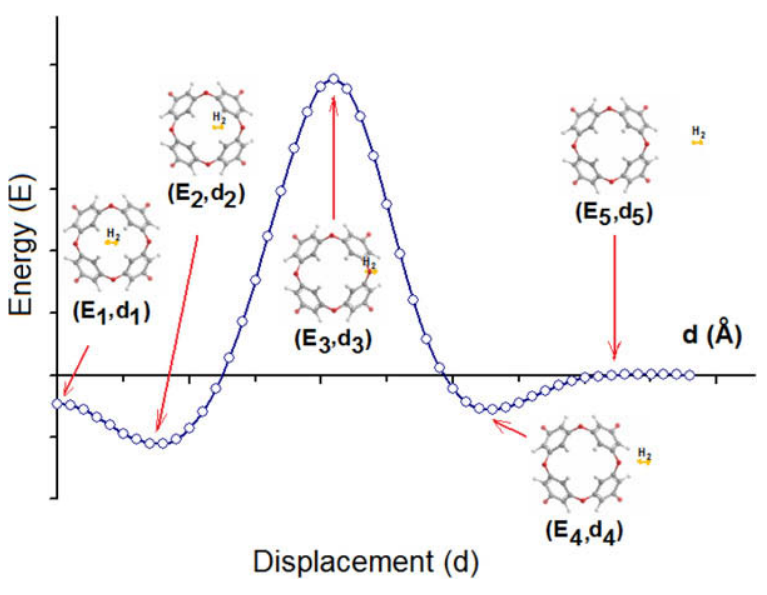

Scheme 3. Profile of the potential energy surface.

(Oxa3), $4.000 \AA$ (Meth2), and $4.412 \AA$ (Thia4) [20]. The energy barriers $E_{23}$ and $E_{43}$ obtained at B3LYP are smaller than those obtained at M05-2X and HF overestimates them.

The methods HF, B3LYP, and M05-2X show almost the same values of the distances $d_{3}$, Scheme 3 , which is the position of the energy barrier. $d_{3}$ (in $\AA$ ) is in the range $3.56-3.60$ in the case of Spher1, 4.17-4.20 for Meth2, 3.83-3.90 for Oxa3, and 4.00-4.17 for Thia4.

\subsubsection{C-approach}

The variation of the total interaction energies of the systems $\left(\mathrm{H}_{2}\right.$, Spher) have been studied in function of the intermolecular distance $d$ when a hydrogen molecule enters in the spherophane following the 6C-appoach, Scheme 2. It has been found that this variation shows the same profile as in Scheme 3 but with very high potential barriers. In our recently published paper [20], we have found that the geometrical structure of the $C_{6}$ cycles in the spherophanes depends on the nature of the linker between the phenyl rings. The benzene rings are not planar but exhibit small distortions. This explains the difference found between the activation energies obtained for the different spherophanes although in each case the hydrogen molecule gets through a benzene ring. The energetic barriers of $\mathrm{H}_{2}$ to enter to the cage, $E_{23}$, and to escape from the cage, $E_{43}$, through a $\mathrm{C}_{6}$ cycle are almost the equal in all the considered systems; $E_{23} \approx E_{43}$, Fig. $3 \mathrm{~b}$.

The energetic barriers are found when the hydrogen molecule is exactly at the middle of the $\mathrm{C}_{6}$ cycle. We got the same value of $d_{3}$ with all the computational used models. This distance is equal to $3.29 \AA, 4.19 \AA, 3.92 \AA$, and $4.40 \AA$ in the case of, respectively, Spher1, Meth2, Oxa3, and Thia4. The difference $d_{4}-d_{3}$ is the equilibrium distance of a hydrogen molecule normally approaching a $\mathrm{C}_{6}$ ring and $E_{4}$ is the corresponding equilibrium interaction energy. At the M05-2X/3-21G level, the couple $\left(d_{4}-d_{3}, E_{4}\right)$ is equal to (3.1, $-1.4)$ in the case of Spher1, $(2.9,-1.7)$ in Meth2, $(3.1,-1.2)$ in Oxa3, and is $(2.9,-1.4)$ in the case of Thia4, $d$ is in $\AA$ and $E$ is in $\mathrm{kcal} / \mathrm{mol}$. Zhechrov et al. [37] have reported, at high ab initio levels of calculation, an equilibrium distance of a perpendicular approach of $\mathrm{H}_{2}$ to a free $\mathrm{C}_{6} \mathrm{H}_{6}$ between 3.1 and $3.3 \AA$ and an interaction energy between -4.7 and $-4.1 \mathrm{kcal} / \mathrm{mol}$. We expected that this difference particularly in the value of the energy with our results could be due to the structures of the $C_{6}$ rings in these spherophanes which are not exactly planar [20] and to the small basis set 3-21G used in these calculations. Hence, we have made rigid scans along the 6C-approach at M05-2X with a larger basis set, 6-31G(d), in the two cases Thia 4 and Oxa3. The obtained distances, $d_{4}-d_{3}$, are $3.2 \AA$ in the case of Oxa3 and 3.1 $\AA$ in Thia4, however, the interaction energies diminish to $-0.9 \mathrm{kcal} / \mathrm{mol}$ in $0 x a 3$ and $-0.9 \mathrm{kcal} / \mathrm{mol}$ in Thia4. This great incoherence between our results and those of Zhechrov et al. [37] has encouraged us to do complete optimizations of the systems $\left(\mathrm{H}_{2}\right.$, Oxa3, $\left.d=d_{4}\right)$ and $\left(\mathrm{H}_{2}\right.$, Thia $\left.4, d=d_{4}\right)$ at M05-2X/6-31G(d). The results are this time good; the equilibrium distances (in $\AA$ ) are 3.0(Oxa3) and 2.9(Thia4) and the interaction energies (in $\mathrm{kcal} / \mathrm{mol}$ ) are $-3.1(\mathrm{Oxa} 3$ ) and -4.3 (Thia4).

\subsubsection{H-approach barrier energies}

The above displayed results suggest that a hydrogen molecule would prefer to follow the $4 \mathrm{H}$-approach to enter into or to exit from the cavity of the spherophane. In order to evaluate more precisely the potential energy barriers that a hydrogen molecule has
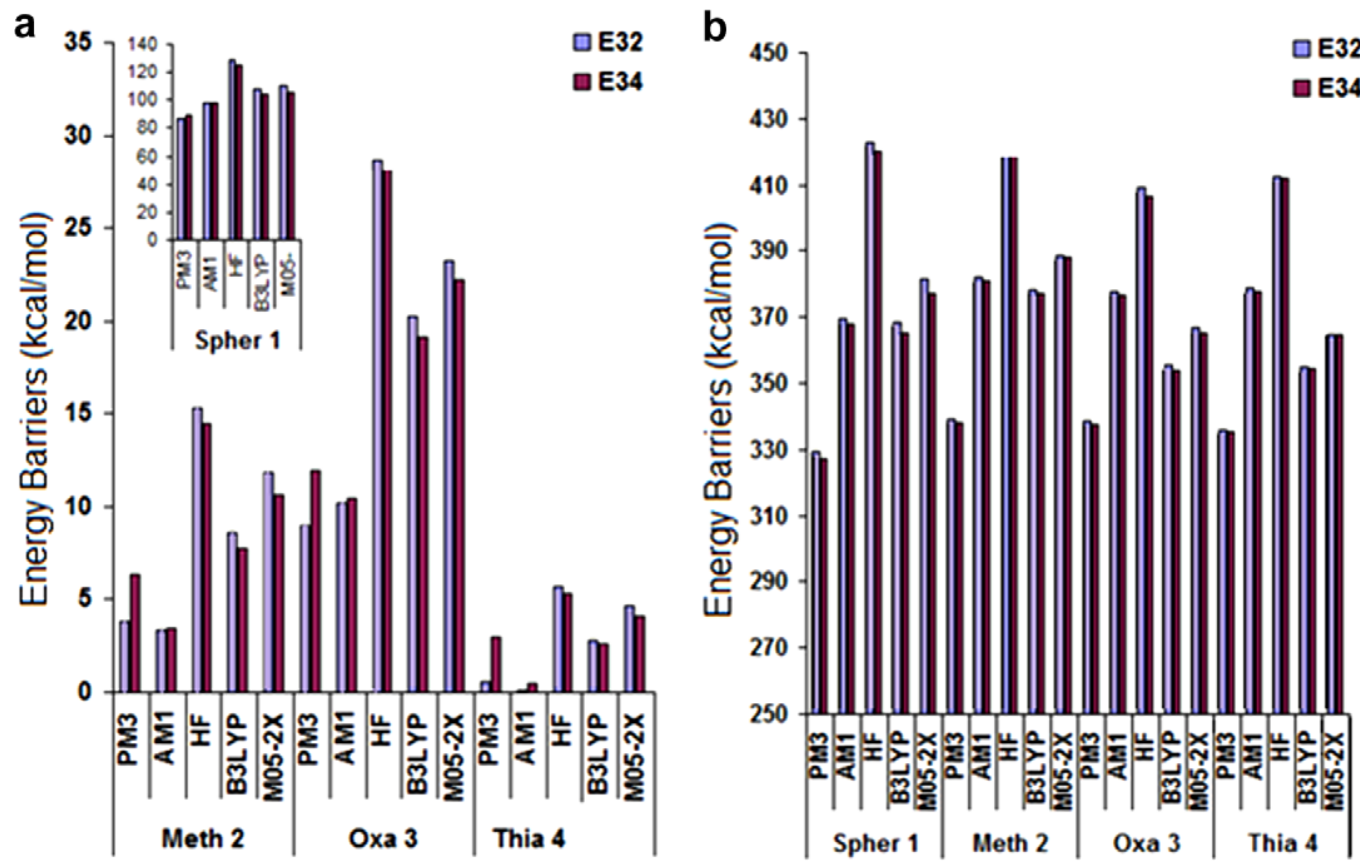

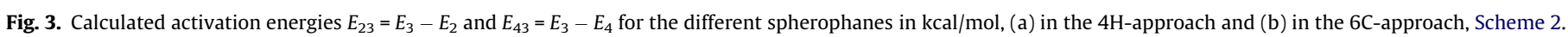


to surpass to get into (or to release from) the cage, complete optimizations of the geometrical structures of the systems $\left(\mathrm{H}_{2}\right.$, Spher1), $\left(\mathrm{H}_{2}\right.$, Meth2), $\left(\mathrm{H}_{2}, \mathrm{Oxa} 3\right)$, and $\left(\mathrm{H}_{2}\right.$, Thia4) have been made at M05-2X/6-31G(d). We have considered the five important cases for each system corresponding to the distances $d_{1}, d_{2}, d_{3}, d_{4}$, and $d_{5}$, cf. Scheme 3. The obtained results are plotted in Fig. 4.

Fig. 4 shows that the minima inside the cavities of the small spherophanes Spher1 and Oxa3 have been found to be very close to their centers. The distance $d_{2}$ is equal to 1.37 and $1.44 \AA$ in the case of Meth2 and Thia4, respectively. The obtained results show that he insertion of an $\mathrm{H}_{2}$ molecule inside the spherophanes stabilizes the systems $\left(\mathrm{H}_{2}\right.$, Spher1), $\left(\mathrm{H}_{2}\right.$, Meth2), $\left(\mathrm{H}_{2}\right.$, Oxa3), and $\left(\mathrm{H}_{2}\right.$, Thia 4 ) by $-5.43,-1.98,-3.23$, and $-1.91 \mathrm{kcal} / \mathrm{mol}$, respectively.

The calculated activation energy barriers for a hydrogen molecule release and insertion in the spherophanes are given in Table

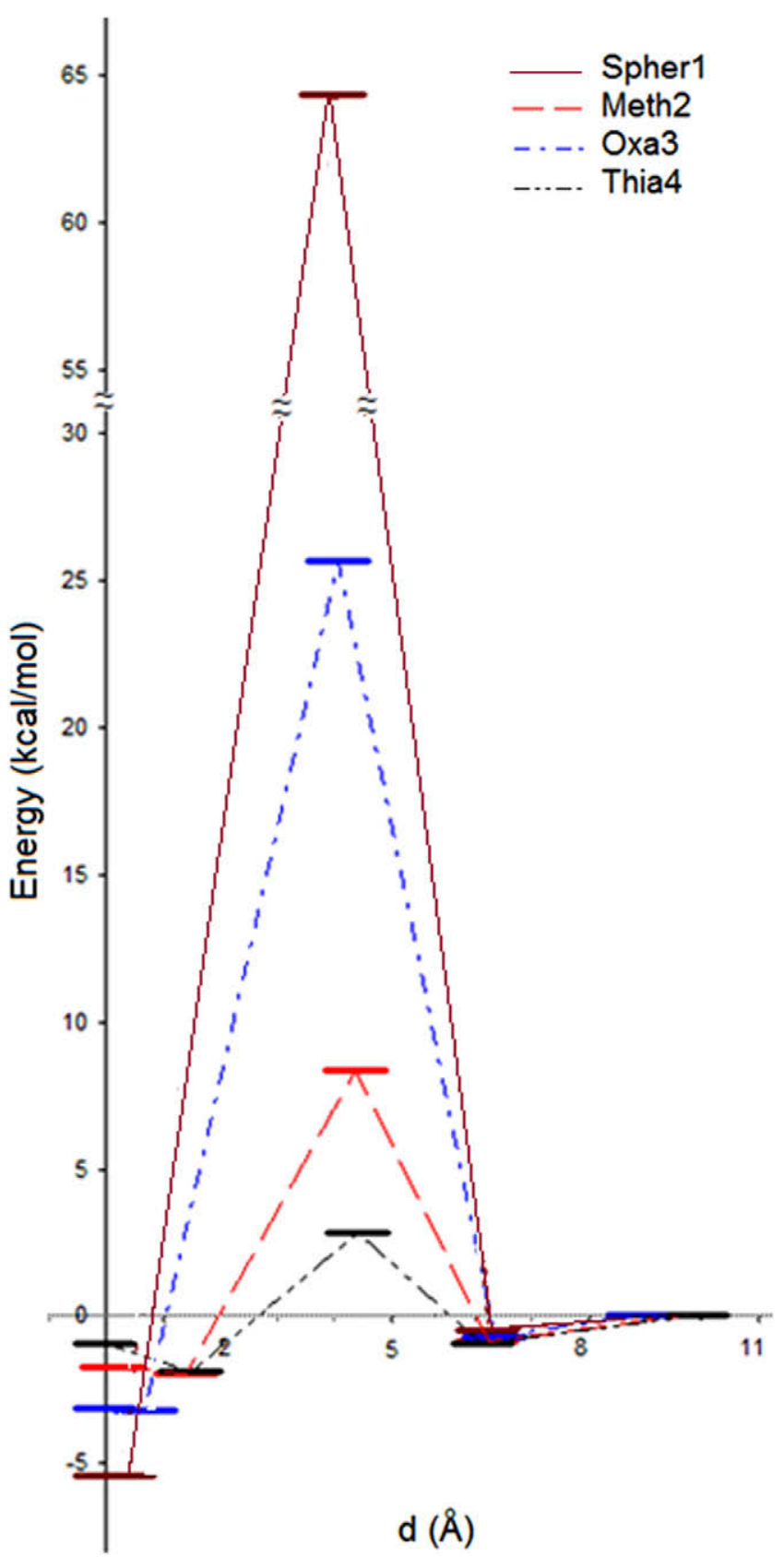

Fig. 4. The energetic diagrams of the systems $\left(\mathrm{H}_{2}\right.$, Spher) obtained after complete optimizations made at M05-2X/6-31G(d) at the different distances $d_{1}, d_{2}, d_{3}, d_{4}$, and $d_{5}$, Scheme 3 , in the $4 \mathrm{H}$-approach.
1. We have also given in this table those of some opens $C_{60}$ and open $C_{70}$ for comparison, Fig. 5 . The values of the energy barrier, $E_{43}$, for a hydrogen molecule to enter into the spherophane cage via the $4 \mathrm{H}$-approach is $64.84,9.24,26.32$, and $3.69 \mathrm{kcal} / \mathrm{mol}$ in the case of Spher1, Meth2, Oxa3, and Thia4, respectively. While the insertion activation energy, in $\mathrm{kcal} / \mathrm{mol}$, is 30.13 [11], and 41.45 [10], for different open $C_{60}$ and is 31.2 for open $C_{70} 1$ [5]. The corresponding barriers $E_{32}$, for $\mathrm{H}_{2}$ release from the cages are, in $\mathrm{kcal} / \mathrm{mol}: 69.75,10.36,28.77$, and 4.70 in the cases of Spher1, Meth2, Oxa3, and Thia4, respectively. Whereas the activation energy $\left(\mathrm{kcal} / \mathrm{mol}\right.$ ) for $\mathrm{H}_{2}$ release from different open $\mathrm{C}_{60}$ is equal to $21.7 \pm 0.42$ [4], $34.3 \pm 0.73$ [11], $32.4 \pm 0.74$ [12], and 40.05 [10], and from open $C_{70} 1$ [5], it is of $33.8 \pm 0.1 \mathrm{kcal} / \mathrm{mol}$.

The localisation of the transition structures, $d=d_{3}$, has been made with the quadratic synchronous transit approach requested by the QST3 keyword which uses the Synchronous Transit-guided Quasi-Newton (STQN) method as implemented in GAUSSIAN 03 [36]

Table 1

The energies of a hydrogen molecule insertion in and release from the spherophanes evaluated at M05-2X/6-31G(d) are given in $\mathrm{kcal} / \mathrm{mol}$ in parallel with those of some open fullerenes.

\begin{tabular}{llll}
\hline Molecule & Release energy & Insertion energy & Reference \\
\hline Spher1 & $69.75^{\mathrm{a}}$ & $64.84^{\mathrm{a}}$ & \\
Meth2 & $10.36^{\mathrm{a}}$ & $9.24^{\mathrm{a}}$ & \\
Oxa3 & $28.77^{\mathrm{a}}$ & $26.32^{\mathrm{a}}$ & \\
Thia4 & $4.70^{\mathrm{a}}$ & $3.69^{\mathrm{a}}$ & {$[5]$} \\
1 & $33.8 \pm 0.1$ & $31.2^{\mathrm{b}}$ & {$[4]$} \\
2 & $21.7 \pm 0.4\left(19.8^{\mathrm{b}}\right)$ & & {$[11]$} \\
3 & $34.3 \pm 0.7$ & $30.1^{\mathrm{b}}$ & {$[12]$} \\
4 & $32.4 \pm 0.7\left(28.2^{\mathrm{b}}\right)$ & $29.9^{\mathrm{b}}$ & {$[10]$} \\
5 & $40.0^{\mathrm{b}}$ & $41.4^{\mathrm{b}}$ & \\
\hline
\end{tabular}

a Calculated at M05-2X/6-31G(d)

b Calculated at B3LYP/6-31G**//B3LYP/3-21G

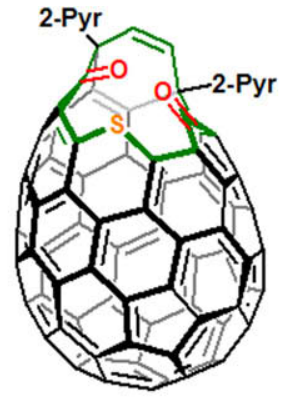

1

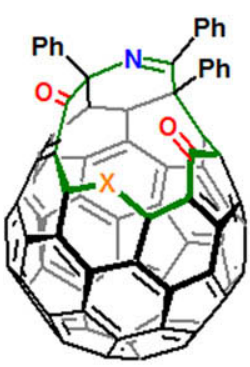

$3, X=S$ $4, X=S e$

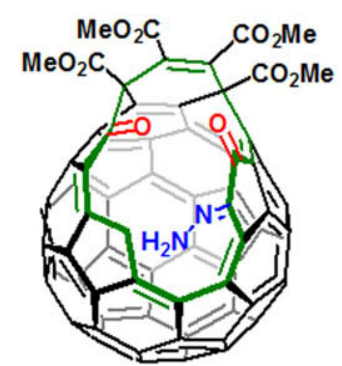

2

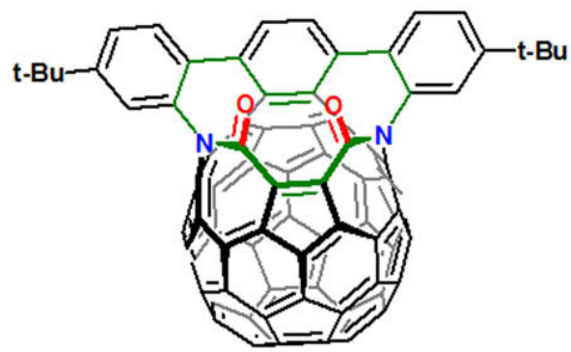

5
Fig. 5. Some open cage fullerenes studied in the literature: 1 open $C_{70}$ [5], 2 open $C_{60}[4], 3$ open $C_{60}[11], 4$ open $C_{60}[12]$, and 5 open $C_{60}[10]$. 

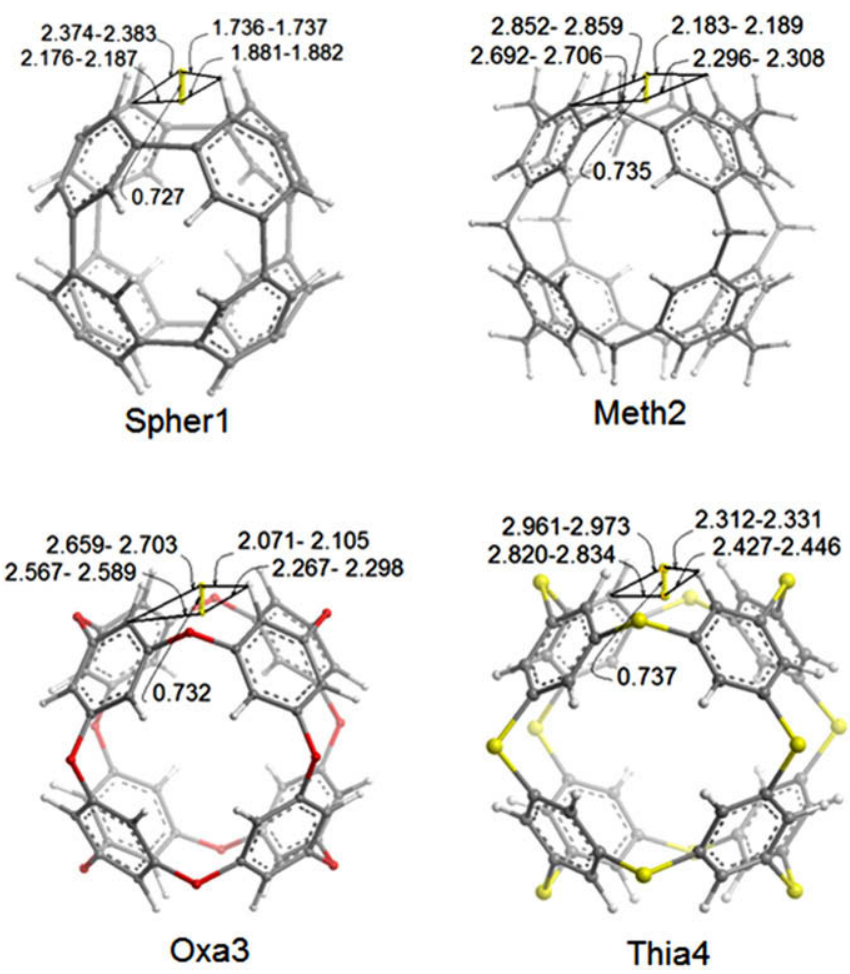

Fig. 6. The optimized transition structures, $d=d_{3}$, obtained with the QST3 keyword implemented in GaUSSIAN 03 [36] at M05-2X/6-31G(d).

at M05-2X/6-31G(d) level. This has been followed by a frequency calculation at M05-2X/6-31G(d). All the optimized structures show one imaginary frequency which means that we are at the searched transition structure. The distances of the hydrogen molecule with the nearest atoms at the entrance of the spherophanes are given in Fig. 6.

\section{Conclusion}

We have studied in this work a hydrogen molecule insertion into and release from the spherophanes. The energetic barriers have been determined and compared to those of open $C_{60}$ and open $\mathrm{C}_{70}$ cages.

It has been found that the dispersion interactions play an important role in these systems; they govern their stability and the potential energy barriers. The results obtained at the metaGGA hybrid density functional M05-2X/6-31G(d) show that: unlike open $C_{70}$ [5] or some other studied molecular cages such as $B_{36} N_{36}$ [3], the insertion of a hydrogen molecule inside these spherophanes is stabilizing. When $\mathrm{H}_{2}$ is at the center of the spherophane, due to cooperative contributions, the system $\left(\mathrm{H}_{2}\right.$, Spher1) have been found to be more stable than the systems $\left(\mathrm{H}_{2}\right.$, Meth2), $\left(\mathrm{H}_{2}\right.$, Oxa3), and $\left(\mathrm{H}_{2}\right.$, Thia4). It has also been found that the activation energy barriers to get into (to release from) the spherophanes' cavities decrease in the order Spher1, Oxa3, Meth2, and Thia4. The insertion (release) of a hydrogen molecule into (from) the spherophanes Meth2, Oxa3, and Thia4 are less energy demanding than they are in the case of open $C_{60}$ [4,10-12] and open $C_{70}$ [5]. Finally, it could be predicted from this study that Meth2 and Thia4 could be good candidates for $\mathrm{H}_{2}$ storage applications. The capacity of these spherophanes to store molecular and/or atomic hydrogen is under study.

\section{Acknowledgements}

Amar Saal thanks le Ministère Algérien de l'Enseignement Supérieur et de la Recherche Scientifique (MESRS) for Financial support and the University of Fribourg for infrastructure.

\section{References}

[1] A.C. Dillon, K.M. Jones, T.A. Bekkedahl, C.H. Kiang, D.S. Bethune, M.J. Heben, Nature 386 (1997) 377.

[2] G. Mpourmpakis, G.E. Froudakis, G.P. Lithoxoos, J. Samios, Nano Lett. 6 (2006) 1581.

[3] Q. Sun, Q. Wang, P. Jena, Nano Lett. 5 (2005) 1273.

[4] S. Iwamatsu, S. Murata, Y. Andoh, M. Minoura, K. Kobayashi, N. Mizorogi, S. Nagase, J. Org. Chem. 70 (2005) 4820.

[5] Y. Murata, S. Maeda, M. Murata, K. Komatsu, J. Am. Chem. Soc. 130 (2008) 6702 .

[6] Z. Zhou, J. Zhao, Z. Chen, X. Gao, T. Yan, B. Wen, P.R. Schleyer, J. Phys. Chem. B 110 (2006) 13363.

[7] A. Kuc, L. Zhechkov, S. Patchkovskii, G. Seifert, T. Heine, Nano Lett. 7 (2007) 1.

[8] S.C. Chuang, Y. Murata, M. Murata, K. Komatsu, J. Org. Chem. 72 (2007) 6447.

[9] R.J. Baierle, P. Piquini, T.M. Schmidt, A. Fazzio, J. Phys. Chem. B 110 (2006) 21184.

[10] Y. Rubin et al., J. Angew. Chem. Int. Ed. 40 (2001) 1543.

[11] Y. Murata, M. Murata, K. Komatsu, J. Am. Chem. Soc. 125 (2003) 7152.

[12] S.C. Chuang, Y. Murata, M. Murata, S. Mori, S. Maeda, F. Tanabe, K. Komatsu, Chem. Commun. (2007) 1278.

[13] D.J. Cram, Ed. Engl. 27 (1988) 1009.

[14] R. Warmouth, J. Yoon, Acc. Chem. Res. 34 (2001) 95 (and references therein).

[15] J. Yoon, C. Sheu, K.N. Houk, C.B. Knobler, D.J. Cram, J. Org. Chem. 61 (1996) 9323.

[16] R.C. Helgeson, C.B. Knobler, D.J. Cram, J. Am. Chem. Soc. 119 (1997) 3229.

[17] R. Wyler, J. de Mendoza, J. Rebek Jr., Angew. Chem. Int. Ed. Engl. 32 (1993) 1699.

[18] R.S. Meissner, J. Rebek Jr., J. de Mendoza, Science 270 (1995) 1485.

[19] M. Fujita, D. Oguro, M. Miyazawa, H. Oka, K. Yamaguchi, K. Ogura, Nature 378 (1995) 469.

[20] A. Saal, T. Jarrosson, C.A. Daul, O. Ouamerali, J. Mol. Mod. 15 (2009) 1067.

[21] M.J.S. Dewar, E.G. Zoebisch, E.F. Healy, J. Am. Chem. Soc. 107 (1985) 3902.

[22] J.J.P. Stewart, J. Comput. Chem. 10 (1989) 221.

[23] C.C. Roothan, J. Rev. Mod. Phys. 23 (1951) 69.

[24] J.A. Pople, R.K. Nesbet, J. Chem. Phys. 22 (1954) 571.

[25] R. McWeeny, G. Dierksen, J. Chem. Phys. 49 (1968) 4852.

[26] A.D. Becke, Phys. Rev. A 38 (1988) 3098.

[27] C. Lee, W. Yang, R.G. Parr, Phys. Rev. B 37 (1988) 785.

[28] Y. Zhao, N.E. Schultz, D.G. Truhlar, J. Chem. Theory Comput. 2 (2006) 364.

[29] S. Grimme, J. Comput. Chem. 25 (2004) 1463.

[30] S. Grimme, J. Comput. Chem. 27 (2006) 1787.

[31] C.A. Morgado, J.P. McNamara, I.H. Hillier, N.A. Burton, M.A. Vincent, J. Chem. Theory Comput. 3 (2007) 1656.

[32] Y. Zhao, D.G. Truhlar, J. Phys. Chem. A 108 (2004) 6908.

[33] Y. Zhao, D.G. Truhlar, J. Phys. Chem. A 109 (2005) 5656.

[34] Y. Zhao, O. Tishchenko, D.G. Truhlar, J. Phys. Chem. B 109 (2005) 19046.

[35] Y. Zhao, D.G. Truhlar, Acc. Chem. Res. 41 (2008) 157.

[36] M.J. Frisch et al., Gaussian 03, Revision E.01, Gaussian, Inc., Wallingford CT, 2004.

[37] L. Zhechkov, T. Heine, S. Patchkovskii, G. Seifert, H.A. Duarte, J. Chem. Theory Comput. 1 (2005) 841. 